\title{
Field Demonstration of a Membrane Process \\ to Recover Heavy Hydrocarbons and to Remove Water from Natural Gas
}

\author{
1999 Annual Report \\ Contract Number DE-FC26-99FT40723 \\ Report Period: September 30 to December 31, 1999 \\ by
}

Membrane Technology and Research, Inc.

1360 Willow Road

Menlo Park, CA 94025

April 4, 2000

prepared for

the U.S. Department of Energy

Morgantown Energy Technology Center Morgantown, WV

Contributors to this Report:

K.A. Lokhandwala

T. Hofmann

J. Kaschemekat

C. Bailey

M. Jacobs

R. Baker

Membrane Group 


\section{INTRODUCTION}

The objective of this project is to design, construct and field demonstrate a 3-MMscfd membrane system to recover natural gas liquids (NGL) and remove water from raw natural gas. An extended field test to demonstrate system performance under real-world conditions is required to convince industry users of the efficiency and reliability of the process. The system will be designed and fabricated by Membrane Technology and Research, Inc. (MTR) and then installed and operated at British Petroleum (BP)-Amoco's Pascagoula, MS plant. The Gas Research Institute will partially support the field demonstration and BP-Amoco will help install the unit and provide onsite operators and utilities. The gas processed by the membrane system will meet pipeline specifications for dewpoint and Btu value and can be delivered without further treatment to the pipeline. Based on data from prior membrane module tests, the process is likely to be significantly less expensive than glycol dehydration followed by propane refrigeration, the principal competitive technology. At the end of this demonstration project the process will be ready for commercialization. The route to commercialization will be developed during this project and may involve collaboration with other companies already servicing the natural gas processing industry.

\section{PROGRESS IN CALENDAR YEAR 1999}

This two-year project started on September 30, 1999. The work accomplished during the period September 30 to December 31, 1999 is summarized by task below.

\section{Task 4.0 Develop Field Test Plan}

During 1999, we visited the BP-Amoco Gas Processing Plant at Pascagoula, MS to finalize the agreement to host the field test and to determine the specific needs and requirements of the plant regarding the skid design and components. This meeting was also attended by GRI (Gas Research Institute), Chevron and BP-Amoco personnel. The specific location for the membrane system in the plant was discussed.

The Pascagoula Gas Plant in Mississippi is reputed to be one of the largest in the United States when fully completed. It will process more than 1.5 billion scf of gas per day, coming mainly from offshore Gulf Coast installations. The plant comprises two trains of turbo expanders and associated equipment. MTR's test skid used for a prior field test at Lost Hills, CA will be refurbished for the Pascagoula test.

Feed gas enters the plant from the main truckline (Destin Pipeline) and passes through a series of slug catchers. The gas, at $1,000 \mathrm{psig}$, is then dehydrated in molecular sieve beds to reduce the water content prior to entering into the cold section. The feed for the membrane system will be taken as a slip stream after the molecular sieves. The maximum flow rate will be about $2.5 \mathrm{MMscfd}$ (the plant will be processing between 500 and 1,000 MMscfd by the time the test begins). The calculated feedgas dewpoint from the numbers provided by the plant is only about $40^{\circ} \mathrm{F}$, so the gas is quite lean. The membrane system feed gas will pass through a particulate filter and a two-phase separator. The 
separated gas will be scrubbed and passed through a Dollinger coalescing filter, and will then enter two module tubes, each holding two elements. This configuration reduces the pressure drop across the elements to a manageable $10 \mathrm{psi}$; four elements in series would result in a pressure drop of more than 50 psi. Here we have assumed that the thickness of the silicone rubber selective layer of the composite membrane is $15 \mu \mathrm{m}$, as calculated under actual operating conditions. (The flux of a nominal $10-\mu \mathrm{m}$ silicone rubber membrane module was $117 \times 10^{-6} \mathrm{~cm}^{3}(\mathrm{STP}) / \mathrm{cm}^{2} \cdot \mathrm{s} \cdot \mathrm{cmHg}$ at the Lost Hills site.)

The Joule-Thomson (J-T) cooling in the residue gas from the membrane unit will be used to cool the permeate after it has been recompressed, which will allow liquids to drop out. The permeate stream will be compressed in a two-stage reciprocating compressor with a power between 200 and $250 \mathrm{hp}$. The condensed liquids will be routed to the de-methanizer after being mixed with the flashed residue gas at 500 psig. This ensures that all gas is processed in the plant and essentially no loss of liquids revenue occurs. We will monitor the liquid production rate.

A detailed test plan will be prepared once the compressor fabricator and compressor details are finalized.

\section{Task 5.1 Prepare Membranes and Modules}

The following plan has been prepared for the production of the membrane and modules required to conduct this test.

\section{Membrane Group}

Estimated Number of Membrane Rolls: $\quad 5$ (for $12 \times 8$-inch elements)

Nominal Membrane Thickness: $\quad 15 \mu \mathrm{m}$. Expected pure gas methane flux of $55 \times 10^{-6}$ $\mathrm{cm}^{3}(\mathrm{STP}) / \mathrm{cm}^{2} \cdot \mathrm{s} \cdot \mathrm{cmHg}$.

Membrane Configuration:

Polyetherimide/silicone rubber(preferably single coat to avoid delamination on swelling)

\section{Module Group}

Number of 8-inch Elements: 12

Required date:

June 2000

Module Hardware:

From existing system

Endcaps:

Modified pressure-drop-resistant end-cap design

Module Configuration:

Standard high-pressure spacers, tapeless module design

Module Area:

Standard 8-inch 


\section{Task 5.2 Design and Construct Field Demonstration System}

The existing membrane skid will be modified to meet the needs of this field demonstration. A preliminary P\&ID has been prepared and the performance of the system under the expected field conditions has been determined. The following tasks, to be completed between April 2000 and June 2000, were identified:

- $\quad$ Prepare new P\&ID

- $\quad$ Change piping to move module housing inlet close to coalescer

- $\quad$ Remove/change feed flow control needle valves

- Update flow monitoring instrumentation

- Relocate pressure gauges to ensure pressures drops can be measured in each tube independently

- Confirm size of coalescer for new duty

- $\quad$ Confirm size of two-phase separator for new duty

- $\quad$ Modify level gauges on two-phase separator to allow control of liquids discharge

- $\quad$ Fix auto drain on coalescer into skid

- $\quad$ Tie in heat tracing to allow single connection from site

- Incorporate particulate filter on skid

- $\quad$ Purchase new compressor

The main issue still to be resolved is the selection of the compressor. The following fabricators provided bids for the compressor:

1. Allen-Stuart/Gardner Denver, Houston, TX

2. EDTI, Corona, CA

3. VR Systems, Corpus Christi, TX

4. Enerflex, Houston, TX

5. Hanover Company, Houston, TX

6. Dresser Rand, Houston, TX

We had selected the compressor fabricator based on our initial discussions with BP-Amoco in January, 2000. However, BP-Amoco decided to impose further standards for the compressor, which delayed obtaining updated quotes. Subsequently, we were informed that our selected fabricators (VR Systems and Allen Stuart) were not acceptable to BP-Amoco because they are not on their preferred suppliers lists and are, therefore, not qualified. They then provided the names of their preferred compressor fabricators, and the process of bidding and bid evaluation was restarted. We expect to make a final decision on the compressor manufacturer by the second week of April, 2000.

\section{Task 5.3 Install System at Site/Initial Evaluation}

No Activity 


\section{Task 5.4 Operate System Continuously}

No Activity

\section{Task 5.5 Survey Industry Users/Analyze Economics}

A detailed list of questions to be asked at meetings with potential users was prepared to ensure that we obtain a better understanding of the natural gas market. These are attached as Appendix 2.

To date, we have surveyed the following companies:

1. Texaco

2. Mobil

3. CONOCO

4. Marathon Oil Company

5. Vastar Resources

6. Various (GPA North Texas Regional Meeting)

7. Kvaerner Process Systems (Formerly Grace Membranes)

8. UOP, Separex

9. Flowtronex

The results of the survey are being incorporated into a database which will provide the information needed to develop a marketing strategy for the natural gas processing industry.

In addition, we have also consulted with Mr. Carter Tannehill of Purvin and Gertz, Inc. Dallas, TX, who is a known expert in the gas processing area. He provided a detailed report on the gas processing technology currently used and its advantages, disadvantages, and costs. The report also included suggestions for potential marketing partners in the gas processing area for MTR's technology.

\section{Task 5.6 Develop Commercialization Plan}

One of the steps in developing the commercialization plan, namely, market definition has been started. We are also developing a marketing strategy; details of these developments will be provided in future reports.

\section{Task 6.0 Final Report/Conference Presentation}

We submitted a paper for the GPA conference in Atlanta. We have also been invited to present a paper at the North Texas GPA meeting. 


\section{APPENDIX 1}

Questions for Natural Gas Processing Industry Contacts

1. What percentage of new wells are rich and what percentage are lean?

2. How many new wells per year?

3. What size?

4. Who are the major players - engineering companies, operating companies, propane refrigeration, other?

5. Any up-and-coming new players?

6. How do approach a project?

7. What do you think other companies do?

8. Do you work with UOP?

9. How do you make a decision to open a well?

10. How do you make a decision to treat the gas?

11. What is the industry preference, lease or buy, old or new?

12. Is there a retrofit market?

13. Why and where?

14. How long do wells typically last?

15. Is there a season or time of year to open new wells?

16. How long is the decision-making process to open new wells?

17. Are refrigeration plants seen as complicated, easy to operate, high maintenance, reliable, etc.?

18. What do you see as major concerns, problems with refrigeration?

19. Is the industry conservative or are they ready for new technologies?

20. Who calls on the well? Reps, direct sales

21. How do you think we should approach the market?

22. Typically, how long to build a treatment plant?

23. Is time to build important?

24. Is the equipment moved from site to site?

25. Is any one gas company seen as a leader, trend setter, looking for new ways to do things?

26. Which magazines are important?

27. Which trade shows are important?

28. Which conferences are important?

29. How do we get maximum exposure of technology?

30. Is there an association we should join?

31. If we partnered with another company, would that be positive or negative?

32. Any partner suggestions?

33. Who are the influential people and decision makers in the operating companies? What is the decision-making process?

34. Is there a recognized technical or marketing industry expert who could bless a technology?

35. Who has the largest installed base among compressor manufacturers?

36. How do we find out about new wells to be brought on-stream?

37. Why do operators open smaller wells?

38. What are the industry trends? 
39. Any constraints on sale of liquids: transportation, storage distance to fractionation, seasonality?

40. Do you see any difference in compressor suppliers?

41. What after-market support is required or requested by operators?

42. What are the key drivers for offshore operations?

43. How important is space and weight and what \$ premium can be attributed to it?

44. Are there specific gas processing requirements offshore that differ from onshore processing?

45. How important are lead times for equipment supply in offshore applications?

46. What are relevant publications read by offshore engineers and fabricators?

47. How are offshore projects approached?

48. How do equipment suppliers get into the design of the systems and at what point and through whom?

49. How are offshore facilities powered?

50. Are there preferred industry standard turbine manufacturers and suppliers/packages?

51. In what places is fuel conditioning considered important?

52. Are there any recurrent maintenance-related issues in gas turbine operations that are frequently cited?

53. Are there any preferred fuel gas compressor suppliers?

54. How and when are gas engines considered as drivers?

55. Are there any suppliers strongly preferred by the industry?

56. Are there any fuel-related issues in operating these gas engines?

57. About what fraction of gas engines are used in powering compressors for raw gas in gathering systems?

58. How important is on-stream time for users of such gas engines? 